\title{
GMR
}

\section{Molecular cloning and expression pattern of the porcine 5-aminolevulinate synthase 1 (ALAS1) gene and its association with reproductive traits}

\author{
L.Q. Liu', F.E. Li ${ }^{2}$ and C.Y. Deng ${ }^{2}$ \\ ${ }^{1}$ Institute of Animal Sciences and Veterinary Medicine, \\ Anhui Academy of Agricultural Sciences, Hefei, Anhui, China \\ ${ }^{2}$ Key Laboratory of Pig Genetics and Breeding of Ministry of \\ Agriculture and Key Laboratory of Agricultural Animal Genetics, \\ Breeding and Reproduction of Ministry of Education, \\ Huazhong Agricultural University, Wuhan, Hubei, China \\ Corresponding author: C.Y. Deng \\ E-mail: 369382985@qq.com
}

Genet. Mol. Res. 15 (1): gmr.15017544

Received August 28, 2015

Accepted October 30, 2015

Published February 19, 2016

DOI http://dx.doi.org/10.4238/gmr.15017544

ABSTRACT. 5-Aminolevulinate synthase 1 (ALAS1) is the first enzyme in the heme biosynthetic pathway and is upregulated in follicular tissue during the early stages of ovulation. In this study, we isolated the complete coding sequence of the porcine ALAS1 gene and its 2-9 intron sequence, identified a single nucleotide polymorphism (SNP; T/C) in intron 9, and developed a PCR-Mspl-restriction fragment length polymorphism genotyping assay. Association of the SNP with litter size was assessed in two populations [purebred Large White and the experimental synthetic (DIV) line]. Statistical analysis demonstrated that for total number of piglets born (TNB) in all parities, pigs with the CC genotype had an additional 0.68 
and 0.74 piglets compared to the TC and TT animals $(P<0.05)$ in the DIV line, respectively. Purebred Large White sows inheriting the CC and TC genotypes gave birth to an additional 0.96 and 0.70 piglets compared to the TT animals $(P<0.05)$ in all parities, respectively. In addition, for TNB in all parities, a significant additive effect of $0.48 \pm 0.23$ and $0.37 \pm 0.17$ piglets/ litter was detected in sows of both populations $(P<0.05)$, respectively. The highest levels of ALAS1 gene expression were observed in isolated ovarian granulosa cells 2 and $12 \mathrm{~h}$ after stimulation with pregnant mare serum gonadotropin human chorionic gonadotropin, which represents the time of follicular development and ovulation, respectively. Therefore, the ALAS1 gene was significantly associated with litter size in two populations and could be a useful molecular marker for the selection of increasing litter size in pigs.

Key words: ALAS1; Porcine; Litter size; Polymorphism

\section{INTRODUCTION}

5-Aminolevulinate synthase 1 (ALAS1), the first and rate-limiting enzyme of the heme pathway, is a member of the a-oxoamine synthase family of pyridoxal 5'-phosphate-dependent enzymes. ALAS1 is best known for its role in catalyzing the condensation of glycine and succinylCoA to yield 5-aminolevulinate, a universal precursor of tetrapyrrole compounds, which is involved in a variety of reactions, including heme biosynthesis, single electron transport, and the catalysis of redox reactions (May et al., 1990; Ferreira and Gong, 1995; Sassa and Nagai, 1996; Oh-Hama, 1997; Thunell, 2000). ALAS1 expression is regulated by heme and by a number of regulatory regions that respond to cellular signals, including those associated with drug responses and nutrition (Fraser et al., 2003; Guberman et al., 2003; Kakizaki et al., 2003; Kaasik and Lee, 2004; Handschin et al., 2005). It is particularly relevant to note that ALAS1 has been associated with mitochondrial P450 cytochromes, and with steroid metabolism and steroid hormone production (Aragonés et al., 1985; May et al., 1990; Thunell, 2000; Ju et al., 2012), i.e., with factors known to be involved in ovulation. In addition, possible functional variants within the $5^{\prime}$-region of the ALAS1 gene mediate an increased transcriptional response in the presence of estrogen and estrogen receptor (du Plessis et al., 2009). In addition, there is limited information to suggest that ALAS1 expression is associated with acute inflammatory reactions (Iwasa et al., 1989; Suhasini et al., 1995). It is possible that ALAS1 expression is an early event in the so-called acute phase response, which is a cascade of overlapping inflammatory pathways activated by tissue injury and/or infection (Suffredini et al., 1999; Lentsch and Ward, 2000). Espey and Richards (2002) reported that ALAS1 is among the first genes to be upregulated in follicular tissue during the early stages of ovulation and is downregulated when the mature ovarian follicles begin to rupture. Hence, ALAS1 might be a functional candidate gene for reproductive traits.

The objective of our study was to examine ALAS1 as a candidate gene for porcine reproductive traits. We isolated the porcine ALAS1 gene, and its 2-9 intron sequences, identified polymorphisms in this gene sequence, investigated allele frequencies, and examined their associations with litter size. Furthermore, the expression pattern of the ALAS1 gene was analyzed by RT-PCR following treatment of ovarian granulosa cells with PMSG/HCG. 


\section{MATERIAL AND METHODS}

\section{Animals and data collection}

All animal procedures were performed according to protocols approved by the Biological Studies of Animal Care and Use Committee of Hubei Province, China. Ovarian tissues were sampled from three 4-month-old Landrace $\mathrm{x}$ Large White sows and then ovarian follicle fluid was collected and used to isolate ovarian granulosa cells. Total DNA and RNA were extracted using phenol chloroform and TRIzol (Invitrogen, Carlsbad, CA, USA), respectively. RNA was reverse transcribed to cDNA using an oligo-dT primer and M-MLV reverse transcriptase (Promega, Madison, WI, USA).

To investigate allelic and genotypic frequencies, 42 Chinese Meishan pigs, 39 Tongcheng pigs, 128 experimental synthetic line (DIV) pigs, 106 Large White' pigs, and 161 Large White" pigs were used.

The association analyses were conducted in two populations with different genetic backgrounds. One population included 267 purebred Large White (106 Large White and 161 Large White") sows kept at the Hubei Academy of Agricultural Sciences research farm and the Experimental Pig Station of Huazhong Agricultural University (HAU), respectively. Another population (DIV line) included 128 sows (101 $\geq 2$ litters per sow in 2005; $82 \geq 2$ litters per sow in 2006) from a synthetic line originating from Landrace, Large White, Tongcheng, and/or Meishan. These animals were reared by HAU. During 2004-2006, both the total number of piglets born (TNB) and the number of piglets born alive (NBA) were recorded in 422 litters of the DIV line sows and 384 litters in purebred Large White sows (140 and 244 litters for Large White' and Large White", respectively). Genomic DNA was extracted from white blood cells according to the methods described by Xiong (1999).

\section{Isolation and culture of ovarian granulosa cells}

Ovarian granulosa cells were cultured as previously described (Yue, 2008). Cells were cultured in Dulbecco's modified Eagle's medium (DMEM)/F12 containing 10\% new calf serum in a $5 \% \mathrm{CO}_{2}, 37^{\circ} \mathrm{C}$ incubator. After $24 \mathrm{~h}$, the culture medium was replaced with $2 \mathrm{~mL} \mathrm{DMEM} / \mathrm{F} 12+2 \mathrm{IU}$ PMSG + 1 IU HCG. The cells were harvested at 0, 2, 4, 8, 12, 16, 20, and $24 \mathrm{~h}$, respectively. Total RNA was extracted and reverse-transcribed to cDNA for use in RT-PCR analysis.

\section{Expression profile of the porcine ALAS1 gene}

Total RNA from the cultured cells $(0,2,4,8,12,16,20$, and $24 \mathrm{~h})$ was extracted and reverse transcription was performed as described above. RT-PCR analysis of the cultured cells was carried out with primer pair 1 (F: 5'-AGGTGTCCGTCTGGTGTA-3', R: 5'-AGAGTGAAGAGGGTTGAG3'), which amplified a fragment spanning the complete coding sequence of the ALAS1 gene. $G A P D H$ was used as an internal control. Primers used for GAPDH amplification were $F$ : 5'-ACCACAGTCCATGCCATCAC-3', R: 5'-TCCACCACCCTGTTGCTGTA-3', which amplified a fragment spanning intron 8 of the GAPDH gene, were applied to exclude the possibility of DNA contamination during all RT-PCRs. PCR conditions were as follows: $94^{\circ} \mathrm{C}$ for $4 \mathrm{~min}$; 30 cycles at $94^{\circ} \mathrm{C}$ for $45 \mathrm{~s} ; 60^{\circ} \mathrm{C}$ for $40 \mathrm{~s}, 72^{\circ} \mathrm{C}$ for $45 \mathrm{~s}$; and a final extension at $72^{\circ} \mathrm{C}$ for $10 \mathrm{~min}$. 


\section{Genomic sequence amplification and sequence analysis}

A porcine expressed sequence tag homologous to human ALAS1 mRNA (GenBank accession No. NM_199166) was used to design primers. PCRs were all performed in a 25- $\mu \mathrm{L}$ reaction volume consisting of $100 \mathrm{ng}$ porcine genomic DNA, 1X buffer, $0.5 \mu \mathrm{M}$ each primer, $100 \mu \mathrm{M}$ each dNTP, and $1 \mathrm{U}$ Taq DNA polymerase (Promega). The PCR parameters were $4 \mathrm{~min}$ at $94^{\circ} \mathrm{C}$, followed by $45 \mathrm{~s}$ at $94^{\circ} \mathrm{C}, 50 \mathrm{~s}$ at the optimal temperature, and $1 \mathrm{~min}$ at $72^{\circ} \mathrm{C}$ for 35 cycles followed by a final extension of $10 \mathrm{~min}$ at $72^{\circ} \mathrm{C}$. The purified PCR products were cloned into the pMD18-T vector (TaKaRa, Tokyo, Japan) and sequenced commercially (Sangon, Shanghai, China). The sequencing results for two Large White and two Meishan pig breeds were compared using BLAST (http://www.ncbi.nlm.nih.gov).

\section{Genetic variation identification and PCR-RFLP analysis}

Based on the BLAST results, a PCR-Mspl-RFLP assay was established to detect the single nucleotide polymorphism (SNP) T/C in intron 9 of the ALAS1 gene. For the PCR-RFLP assay, $8.8 \mu \mathrm{L}$ PCR products amplified by primer pair 2 (F: 5'-CACACCCCGCAGATGATGAC-3', R: 5'-AAATAGAAGTGCAGAGCCCAGC-3') were digested with $6 \mathrm{U} \mathrm{Mspl} \mathrm{(TaKaRa)} \mathrm{for} 4 \mathrm{~h}$ at $37^{\circ} \mathrm{C}$, and then separated by electrophoresis on a $2 \%$ agarose gel (containing ethidium bromide) in $1 \mathrm{XTAE}$ buffer.

\section{Statistical analysis}

The relationship between genotypes and reproductive traits was evaluated using the general linear model procedure in SAS 8.0. Both additive and dominance effects were also estimated using the regression procedure, where the additive effect was estimated as $-1,0$, and 1 for TT, TC, and CC, respectively, and the dominance effect was represented as $1,-1$, and 1 for TT, TC, and CC, respectively (Liu, 1998). The model used was as follows:

$$
\mathrm{Y}_{\mathrm{ijkl}}=\mu+\mathrm{P}_{\mathrm{i}}+\mathrm{S}_{\mathrm{j}}+\mathrm{F}_{\mathrm{k}}+\mathrm{G}_{\mathrm{i}}+\mathrm{e}_{\mathrm{i} \mathrm{jkl}} \quad \text { (Equation 1) }
$$

where, $Y_{i j k l}$ is the observed trait, $\mu$ is the least square means, $P_{i}$ is the effect of the ith parity $[i=1,2$, 3, 4 (parity $\geq 4$ )], $S_{j}$ is the effect of the $j$ th year ( $\mathrm{j}=1$ for 2004, 2 for 2005, and 3 for 2006), $F_{k}$ is the effect of the $k$ th farm $(k=1,2), G$, is the effect of the Ith genotype $(I=1-3)$, and $e_{i j k l}$ is the random residual.

\section{RESULTS}

\section{Sequence obtained and characterization of porcine ALAS1}

A 9137-bp DNA fragment was obtained (GenBank accession No. FJ548763), which contained $54 \mathrm{bp}$ of the 5'-untranslated sequence, 2-9 intron sequences, and the complete open reading fragment encoding a protein of 641 amino acids. The molecular mass of the putative ALAS1 protein was $38.0 \mathrm{kDa}$ and the predicted isoelectric point was 9.07 . Sequence analysis revealed that it contained the complete coding sequence of ALAS1, which showed 89 and $85 \%$ identity in the nucleotide sequence or $100 \%$ identity in the amino acid sequence compared to their counterparts in human (NM_199166.1) and rat (NM_024484.2), respectively. 


\section{Expression analysis of the porcine ALAS1 gene}

Expression analysis using RT-PCR showed that the porcine ALAS1 gene was highly expressed 2 and $12 \mathrm{~h}$ after treatment with PMSG/HCG, which represents the time of follicular development and ovulation, respectively, and the lowest levels were observed 16-24 h, which represents the time of follicle luteinization (Figure 1).

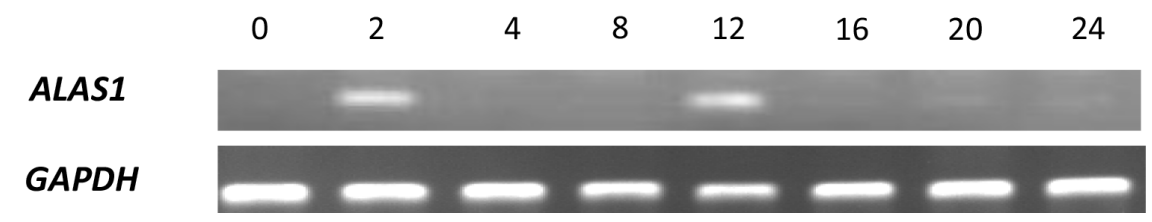

Figure 1. Expression pattern of the porcine ALAS1 gene in granular cell by RT-PCR.

\section{Genetic variation}

Using comparative sequencing of DNA and its unique intron in Large White and Meishan pigs, a T/C mutation in intron 9 was found, which could be detected using the restriction enzyme Mspl (TaKaRa). A 359-bp fragment was amplified with primer pair 2. Allelic forms of porcine ALAS1 were identified as CC (digested by Mspl into 277-, 35-, and 47-bp fragments), TT (324- and 35-bp fragments digested by Mspl), and TC (digested by Mval into 324-, 277-, 35-, and 47-bp fragments) (Figure 2).

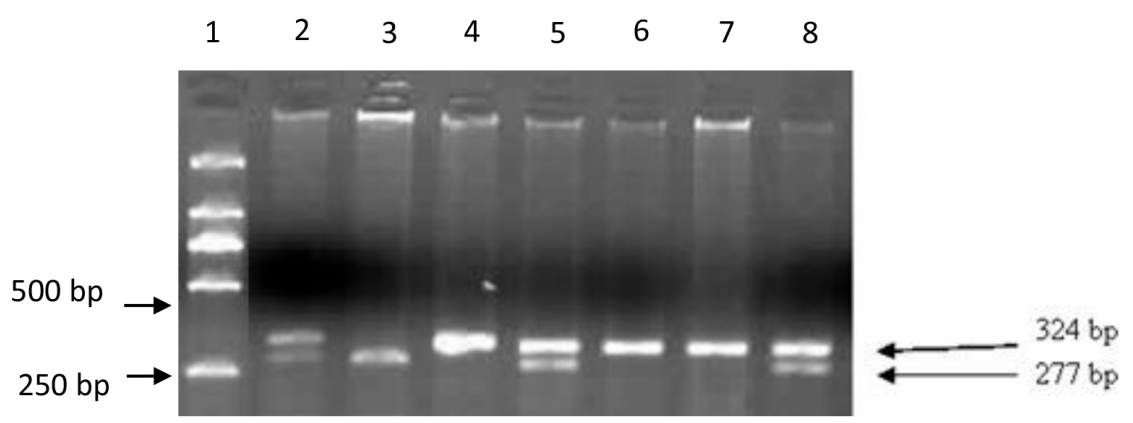

Figure 2. PCR-Mspl-RFLP results of intron 9 with primer pair 2. Lane 1 = DNA molecular marker DL 2000; lanes 2, 5 , 8 = genotype TC; lane 3 = genotype CC; lanes 4, 6, 7 = genotype TT.

\section{Frequency distribution of $A L A S 1$ in different breeds}

Genotypic and allelic frequencies of the SNP were examined in five different populations using PCR-Mspl-RFLP (Table 1). From Table 1, we can conclude that allele frequencies of this polymorphism differ significantly among Chinese and Western pig breeds. Allelic distribution revealed that the Western breeds (Large Whitel and Large White") had higher frequencies of the T allele, sharing 64 and $65 \%$, respectively. In comparison, allele $\mathrm{C}$ was found at higher frequencies of 66 and $95 \%$ in Chinese indigenous breeds (Meishan, Tongcheng), respectively. 
Table 1. Distribution of genotypic and allelic frequencies of the porcine ALAS1 gene PCR-Mspl-RFLP.

\begin{tabular}{l|c|c|c|c|c|c}
\hline \multirow{2}{*}{ Breed } & \multirow{2}{*}{ No. of animals } & \multicolumn{3}{|c|}{ Genotypic frequency } & \multicolumn{2}{c}{ Allelic frequency } \\
\cline { 3 - 6 } & 39 & TT & TC & CC & T & C \\
\hline Tongcheng & $32.05)$ & $0(0)$ & $38(0.95)$ & 0.05 & 0.95 \\
\hline Meishan & 42 & $6(0.14)$ & $17(0.40)$ & $9(0.46)$ & 0.34 & 0.66 \\
\hline Large white & 106 & $46(0.43)$ & $43(0.41)$ & $17(0.16)$ & 0.64 & 0.36 \\
\hline Large white & 161 & $64(0.40)$ & $79(0.49)$ & $18(0.11)$ & 0.65 & 0.35 \\
\hline Experimental synthetic line (DIV) & 128 & $74(0.58)$ & $33(0.26)$ & $21(0.16)$ & 0.71 & 0.29 \\
\hline
\end{tabular}

\section{Association of the polymorphism with porcine reproductive traits}

The results of association analyses between ALAS1 genotypes and litter size traits in Large White and the DIV line sows are given in Table 2. In the first parity, animals of the TC genotype in the DIV sows had 1.39 more piglets born alive than the animals of the TT genotype $(P<0.05)$. For TNB in all parities, pigs with the CC genotype had 0.68 and 0.74 more piglets born than the TC and TT genotype animals $(P<0.05)$ in the DIV line, respectively. Purebred Large White sows inheriting the $C C$ and TC genotypes had 0.96 and 0.70 more piglets born than the TT animals $(P<0.05)$ in all parities, respectively. For NBA in all parities, sows with the CC genotype in the Purebred Large White lines had 1.63 more piglets born than the TT animals $(P<0.01)$, and TC animals had 0.89 more piglets born than the TT animals $(P<0.05)$. In addition, for TNB in all parities, a significant additive effect of $0.48 \pm 0.23$ and $0.37 \pm 0.17$ piglets/litter was detected in both the DIV sows and purebred Large White lines $(P<0.05)$, respectively.

\begin{tabular}{|c|c|c|c|c|c|}
\hline \multirow[t]{2}{*}{ Traits } & \multicolumn{3}{|c|}{ ALAS1 genotype (means $\pm \mathrm{SE})$} & \multicolumn{2}{|c|}{ Effect (means $\pm \mathrm{SE}$ ) } \\
\hline & TT & TC & CC & Additive & Dominance \\
\hline \multicolumn{6}{|c|}{ ALAS1 effects for first parity in purebred Large White pigs } \\
\hline $\mathrm{N}$ & 21 & 20 & 7 & & \\
\hline TNB & $10.190 \pm 0.606$ & $10.400 \pm 0.621$ & $8.857 \pm 1.049$ & $-0.667 \pm 0.606$ & $-0.438 \pm 0.434$ \\
\hline NBA & $8.619 \pm 0.661$ & $8.900 \pm 0.677$ & $8.000 \pm 1.145$ & $-0.310 \pm 0.661$ & $-0.295 \pm 0.473$ \\
\hline \multicolumn{6}{|c|}{ ALAS1 effects for all parities in purebred Large White pigs } \\
\hline $\mathrm{N}$ & 156 & 193 & 66 & & \\
\hline TNB & $9.711 \pm 0.257^{a}$ & $10.414 \pm 0.206^{b}$ & $10.667 \pm 0.391^{\mathrm{b}}$ & $0.478 \pm 0.234^{*}$ & $-0.113 \pm 0.1156$ \\
\hline NBA & $8.198 \pm 0.287^{\mathrm{aA}}$ & $9.083 \pm 0.186^{b}$ & $9.828 \pm 0.479 \mathrm{bB}$ & $0.210 \pm 0.213$ & $-0.045 \pm 0.148$ \\
\hline \multicolumn{6}{|c|}{ ALAS1 effects for first parity in experimental synthetic (DIV) line pigs } \\
\hline $\mathrm{N}$ & 26 & 16 & 10 & & \\
\hline TNB & $10.385 \pm 0.399$ & $10.750 \pm 0.509$ & $11.200 \pm 0.643$ & $0.408 \pm 0.378$ & $0.021 \pm 0.317$ \\
\hline NBA & $8.731 \pm 0.415^{\mathrm{a}}$ & $10.125 \pm 0.528^{b}$ & $9.300 \pm 0.668^{\mathrm{ab}}$ & $0.285 \pm 0.393$ & $-0.555 \pm 0.329$ \\
\hline \multicolumn{6}{|c|}{ ALAS1 effects for all parities in experimental synthetic (DIV) line pigs } \\
\hline $\mathrm{N}$ & 225 & 96 & 64 & & \\
\hline TNB & $11.678 \pm 0.157^{a}$ & $11.737 \pm 0.241^{\mathrm{a}}$ & $12.417 \pm 0.297^{\mathrm{b}}$ & $0.369 \pm 0.168^{*}$ & $0.205 \pm 0.147$ \\
\hline NBA & $10.839 \pm 0.162$ & $10.618 \pm 0.249$ & $10.892 \pm 0.308$ & $0.027 \pm 0.174$ & $0.124 \pm 0.152$ \\
\hline
\end{tabular}

\section{DISCUSSION}

Ovarian granulosa cells play pivotal roles in many aspects of ovarian function, including folliculogenesis and steroidogenesis. The spatial and temporal expression of ALAS1 during HCGstimulated ovulation has been demonstrated (Espey and Richards, 2002) and is associated with mitochondrial P450 cytochromes, steroid metabolism, and steroid hormone production (Aragones et al., 1985; May et al., 1990; Thunell, 2000; Ju et al., 2012). Therefore, we selected ALAS1 as a candidate gene for porcine reproductive traits. 
In this study, we isolated the complete coding region of the porcine ALAS1 gene. It is well known that the gene sequence, especially that of the coding region, is very important for research on gene expression and function. The high amino acid sequence similarity between the porcine ALAS1 gene and its counterparts in mammals reveals the significance and conservation of their biological functions during evolution. Expression pattern analysis revealed that treatment with PMSG/HCG caused a rapid induction of $A L A S 1$ transcription in granulosa cells isolated from preovulatory follicles, which is consistent with the observation. ALAS1 was one of the first in which transcription was upregulated in follicular tissue during the early stages of the ovulatory process and was downregulated when the mature ovarian follicles are beginning to rupture (Espey and Richards, 2002).

In this study, we identified an SNP (T/C) in intron 9 and the polymorphism was significantly associated with TNB and NBA. For TNB in all parities, a significant additive effect $(0.48 \pm 0.23$ and $0.37 \pm 0.17$ piglets/litter; $P<0.05$ ) was detected in both the DIV line and in purebred Large White animals, respectively. Pigs with the CC genotype had more TNB than pigs with the TC and TT genotypes. Thus, increasing the frequency of the $\mathrm{C}$ allele could be beneficial in the DIV line and Large White animals to accelerate the genetic improvement of reproductive traits.

In this study, the polymorphism analyzed in the ALAS1 gene was found in intron 9. Although SNPs in introns do not directly alter the amino acid sequence, they may contain an enhancer or another cis-acting element; thus, constituent SNPs might regulate gene transcription (Bachl et al., 1998) and be directly related to functional variation (Padma et al., 2004). In addition, Nobuyoshi et al. (1997) reported that SNPs in introns may play a role in mRNA splicing and stability. Therefore, variations in ALAS1 sequences may have important regulatory roles and also be directly related to functional variations. A statistical model with additive and dominance effects only is not ideal. We could not assume the effect of sow because of the insufficient data.

This presumable association is restricted to all parity in the purebred Large White pig group. This may be due to two reasons, one is that the number of animals was not sufficient to demonstrate the true event; the other is that this SNP has no effect on reproductive trait components. Therefore, there is a need for further verification.

Although the SNP (T/C) in intron 9 was found to be associated with TNB and NBA, our results were based on a limited number of animals, which suggests that this preliminary result should be confirmed in more pig populations with a large sample size, and the role of ALAS1 in porcine reproductive traits or its linkage disequilibrium with other causative mutations should be investigated. If the effect is steady and functional in other populations, this SNP may be a useful molecular marker for reproductive traits in porcine breeding.

\section{Conflicts of interest}

The authors declare no conflict of interest.

\section{ACKNOWLEDGMENTS}

Research supported by the Dean Young Innovation Fund projects (\#14B0427); the Anhui Academy of Agricultural Science and Technology Innovation team project (\#13c0405); the Modern Agriculture (\#201201); and the National "863" Project of P.R. China (\#2007AA10Z166, \#2007AA10Z162). 


\section{REFERENCES}

Aragonés A, González CB, Lantos CP and Sancovich HA (1985). Progesterone, its A/B cis reduction and delta aminolevulinic acid synthetase in the developing hen. Acta Physiol. Pharmacol. Latinoam. 35: 379-397.

Bachl J, Olsson C, Chitkara N and Wabl M (1998). The Ig mutator is dependent on the presence, position, and orientation of the large intron enhancer. Proc. Natl. Acad. Sci. USA 95: 2396-2399. http://dx.doi.org/10.1073/pnas.95.5.2396

du Plessis N, Kimberg M, Zaahl MG, Sadie A, et al. (2009). Functional analysis of the 5 ' regulatory region of the 5 -aminolevulinate synthase (ALAS1) gene in response to estrogen. Cell. Mol. Biol. (Noisy-le-grand) 55: 20-30.

Espey LL and Richards JS (2002). Temporal and spatial patterns of ovarian gene transcription following an ovulatory dose of gonadotropin in the rat. Biol. Reprod. 67: 1662-1670. http://dx.doi.org/10.1095/biolreprod.102.005173

Ferreira GC and Gong J (1995). 5-Aminolevulinate synthase and the first step of heme biosynthesis. J. Bioenerg. Biomembr. 27: 151-159. http://dx.doi.org/10.1007/BF02110030

Fraser DJ, Zumsteg A and Meyer UA (2003). Nuclear receptors constitutive androstane receptor and pregnane $X$ receptor activate a drug-responsive enhancer of the murine 5-aminolevulinic acid synthase gene. J. Biol. Chem. 278: 3939239401. http://dx.doi.org/10.1074/jbc.M306148200

Guberman AS, Scassa ME, Giono LE, Varone CL, et al. (2003). Inhibitory effect of AP-1 complex on 5-aminolevulinate synthase gene expression through sequestration of CAMP-response element protein (CRE)-binding protein (CBP) coactivator. $J$. Biol. Chem. 278: 2317-2326. http://dx.doi.org/10.1074/jbc.M205057200

Handschin C, Lin J, Rhee J, Peyer AK, et al. (2005). Nutritional regulation of hepatic heme biosynthesis and porphyria through PGC-1alpha. Cell 122: 505-515. http://dx.doi.org/10.1016/j.cell.2005.06.040

Iwasa F, Sassa S and Kappas A (1989). The effects of acute-phase inducers and dimethyl sulphoxide on delta-aminolaevulinate synthase activity in human HepG2 hepatoma cells. Biochem. J. 259: 605-607. http://dx.doi.org/10.1042/bj2590605

Ju Y, Mizutani T, Imamichi Y, Yazawa T, et al. (2012). Nuclear receptor 5A (NR5A) family regulates 5-aminolevulinic acid synthase 1 (ALAS1) gene expression in steroidogenic cells. Endocrinology 153: 5522-5534. http://dx.doi.org/10.1210/ en.2012-1334

Kaasik K and Lee CC (2004). Reciprocal regulation of haem biosynthesis and the circadian clock in mammals. Nature 430: 467-471. http://dx.doi.org/10.1038/nature02724

Kakizaki S, Yamamoto Y, Ueda A, Moore R, et al. (2003). Phenobarbital induction of drug/steroid-metabolizing enzymes and nuclear receptor CAR. Biochim. Biophys. Acta 1619: 239-242. http://dx.doi.org/10.1016/S0304-4165(02)00482-8

Lentsch AB and Ward PA (2000). Regulation of inflammatory vascular damage. J. Pathol. 190: 343-348. http://dx.doi. org/10.1002/(SICI)1096-9896(200002)190:3<343::AID-PATH522>3.0.CO:2-M

Liu BH (1998). Statistical Genomics: Linkage, Mapping and QTL Analysis. CRC press, LLC. American, 404.

May BK, Bhasker CR, Bawden MJ and Cox TC (1990). Molecular regulation of 5-aminolevulinate synthase. Diseases related to heme biosynthesis. Mol. Biol. Med. 7: 405-421.

Nobuyoshi M, Lin XH, Takimoto Y, Deuel TF, et al. (1997). Transcription regulation of the PDGF A-chain gene by first intron elements. Biochem. Biophys. Res. Commun. 230: 569-572. http://dx.doi.org/10.1006/bbrc.1996.6011

Oh-hama T (1997). Evolutionary consideration on 5-aminolevulinate synthase in nature. Orig. Life Evol. Biosph. 27: 405-412. http://dx.doi.org/10.1023/A:1006583601341

Padma B, Kumar P, Choudhary V, Dhraha SK, et al. (2004). Nucleotide sequencing and PCR-RFLP of insulin-like growth factor binding protein-3 gene in Riverine Buffalo (Bubalus bubalis). Asian-Aust. J. Anim. Sci. 17: 910-913.

Sassa S and Nagai T (1996). The role of heme in gene expression. Int. J. Hematol. 63: 167-178. http://dx.doi.org/10.1016/0925$\underline{5710(96) 00449-5}$

Suffredini AF, Fantuzzi G, Badolato R, Oppenheim JJ, et al. (1999). New insights into the biology of the acute phase response. J. Clin. Immunol. 19: 203-214. http://dx.doi.org/10.1023/A:1020563913045

Suhasini M, Boss GR, Pascual FE and Pilz RB (1995). Nitric oxide-releasing agents and cGMP analogues inhibit murine erythroleukemia cell differentiation and suppress erythroid-specific gene expression: correlation with decreased DNA binding of NF-E2 and altered c-myb mRNA expression. Cell Growth Differ. 6: 1559-1566.

Thunell S (2000). Porphyrins, porphyrin metabolism and porphyrias. I. Update. Scand. J. Clin. Lab. Invest. 60: 509-540. http:// dx.doi.org/10.1080/003655100448310

Xiong YZ (1999). Pig Biochemistry and Molecular Genetics: Experimental Introduction. Chinese Agriculture Press, Beijing.

Yue K (2008). Cloning, radiation hybrid mapping, promoter regulation and genetics effect analysis of porcine adamis1 gene. Huazhong Agricultural University, Wuhan. 